\title{
Modifying Apple Tree Canopies for Improved Production Efficiency
}

\author{
Terence L. Robinson, Alan N. Lakso, and Zhongbo Ren ${ }^{1}$ \\ Department of Horticultural Sciences, New York State Agricultural Experiment Station, \\ Cornell University, Geneva, NY 14456
}

\begin{abstract}
Canopy development in perennial crops has a seasonal and a lifetime developmental pattern. The sum of development over individual seasons results in the final canopy dimensions and form. In apple, there is a natural progression from a single-shoot tree toward the tall $(10 \mathrm{~m})$, umbrella-shaped tree (Fig. 1). There are many disadvantages to this large umbrella-shaped tree: 1) it is difficult to spray, prune, and hand-harvest; 2) it has poor distribution of light throughout the canopy; and 3 ) it has a low early life light interception, leaf area index, and fraction of land covered by canopy, leading to delayed cropping. These disadvantages have resulted in widespread efforts to reduce tree size, increase tree density, accelerate canopy and yield development, and improve canopy form to overcome the limitations of the large tree.

In apple, there are several practical approaches to tree size control and canopy modification, including the use of rootstocks, scions, pruning, and tree training. Rootstocks are available that will give a wide range of tree sizes ranging from the $10-\mathrm{m}$ tree described above to fully dwarf trees $<2 \mathrm{~m}$ high. There is also available a range in scion types, ranging from the nonbranching, columnar types to the spreading, nonspur types. In addition, apples respond well to canopy modification by pruning and training. These four variables make possible a myriad of tree forms, planting arrangements, and tree heights, widths, and geometric forms (spheric, rectangular, conic $\mathrm{V}, \mathrm{T}$, and A forms). The practical value of canopy modifications depends on their effect on orchard production efficiency.
\end{abstract}

\section{MEASURES OF EFFICIENCY}

The most important measures of efficiency are total fruit yield or yield of high quality fruit per unit of input (land, capital, labor, light energy, water, or nutrients). The fruit grower is also interested in efficiency expressed in terms of managing the orchard canopy: primarily the efficiency of pruning, spraying, and harvesting the tree. Depending on the perspective, each of these measures of efficiency has value; however, for this paper we will address mainly the fruit yield efficiency of apple canopies.

Yield expressed on a unit of land area is the commonest and simplest measure of efficiency, but it is the integration of many variables. It strongly depends on orchard factors (spacing and tree height : clear alley ratio) and tree factors (scion, rootstock, tree form, and canopy density). Tree spacing and tree height : clear alley ratio primarily affect total light interception and can best be studied by measuring or modeling orchard light interception. However, to separate the effects of tree spacing and tree form requires estimates of yield efficiency expressed on a per tree basis. The most common of these efficiency measurements is kilograms of fruit per unit of trunk cross-sectional area (TCA). However, a more fundamental estimate of efficiency is the efficiency of converting light energy into fruit ( $\mathrm{kg}$ of fruit per unit of light energy intercepted). This index provides a uniform comparison between tree forms that allows extension of the results of a field trial beyond the particular set of spacings used in the study.

Total yield of apples has been shown to be related to total light interception (Jackson, 1980); however, the yield of high quality fruit is not a simple function of light interception. The localized light exposure requirements for apple spur flowering, fruit set, fruit size, and fruit color development require that light be distributed to

${ }^{\mathrm{I}}$ Visiting Scientist. Permanent address: Dept. of Horticultural Science, The Northwestern Agr. Univ., Yangling, Shaanxi, China. all fruiting sites in the canopy (Jackson, 1980; Jackson et al., 1977; Robinson et al., 1983). Consequently, the goal of tree design is to intercept a high proportion of available light and to adequately expose the maximum number of fruiting sites by distributing the light uniformly within the canopy (Lakso et al., 1989b). A high level of light interception can be achieved with a closed canopy; however, the extinction of light, which is proportional to the depth of foliage, leads to unfavorable light exposure of the lower part of closed canopies. Orchard canopy architecture must, therefore, be a matter of compromise: a portion of the incident light must be sacrificed to the orchard floor to provide adequate levels of light exposure for the lower limbs of the canopy. In the study of canopy modification, the effect of tree form is best studied by measuring light distribution within the canopy, while the effect of tree spacing and arrangement is best quantified by measuring total light interception.

\section{TREE FORM AND LIGHT DISTRIBUTION}

Two approaches have been used to improve the light distribution in apple canopies. One is to use relatively natural tree forms that allow light penetration through the canopy by providing many small openings in the foliage such as in the multiple leader, central leader, vertical axis, or slender spindle forms (Heinicke, 1975; Lespinasse and Delort, 1986; McKenzie, 1972; Wertheim, 1968). This approach can be successful, but generally requires a high degree of horticultural skill to manage the growth of the canopy. A second approach is to provide fewer large, permanent openings for light penetration into canopies restricted into geometric forms. Examples are thin restricted planes of foliage such as narrow hedgerows, tree walls, and A, V, or T forms (Chalmers and van de Ende, 1975; Dunn and Stolp, 1987; Hutton et al., 1987; Lakso et al., 1989a; Luckwill, 1978; McKenzie et al., 1978; Palmer, 1988; Rosati, 1978; Tukey, 1978; van den Ende et al., 1987). This approach generally requires severe geoemtric restriction of the canopy, expensive support structures, and significant labor to place and maintain the branches in specific locations. The value of these different tree forms lies in their light distribution properties and the attendant improvements in fruit yields and/or quality.

\section{Round crown trees}

Heinicke (1963) and Looney (1968) showed that in large roundcrowned trees light intensity decreased rapidly with increasing depth of foliage and that lower and center positions of the tree received very low light intensities (6\% to $30 \%$ of full sunlight). The exterior quarter of the tree had a small percentage of the total leaf area yet had a large shading effect on the rest of the tree where the major portion of the leaf surface was located (Fig. 2). Heinicke (1963) proposed that $30 \%$ of full sun serve as a lower limit of desired light level in apple canopies. Jackson (1970) found a more rapid decline in light level with depth of canopy, with light levels reduced to $34 \%$ of full sun within $1 \mathrm{~m}$ of the canopy exterior. He found that the main cropping zone of the tree received a minimum of $35 \%$ full sun, while the more shaded areas produced relatively few fruits. This result has led to the rule of thumb that effective penetration depth of light into unrestricted apple canopies is $\approx 1 \mathrm{~m}$.

Narrow hedgerow trees were studied by Verheij and Verwer (1973) who found average light levels $>50 \%$ of full sunlight occurred only at the top periphery of the canopy. Moving down and inward in the canopy of dense hedgerows, average light levels dropped sharply to $\approx 15 \%$ of full sunlight or less. The light penetration into large 


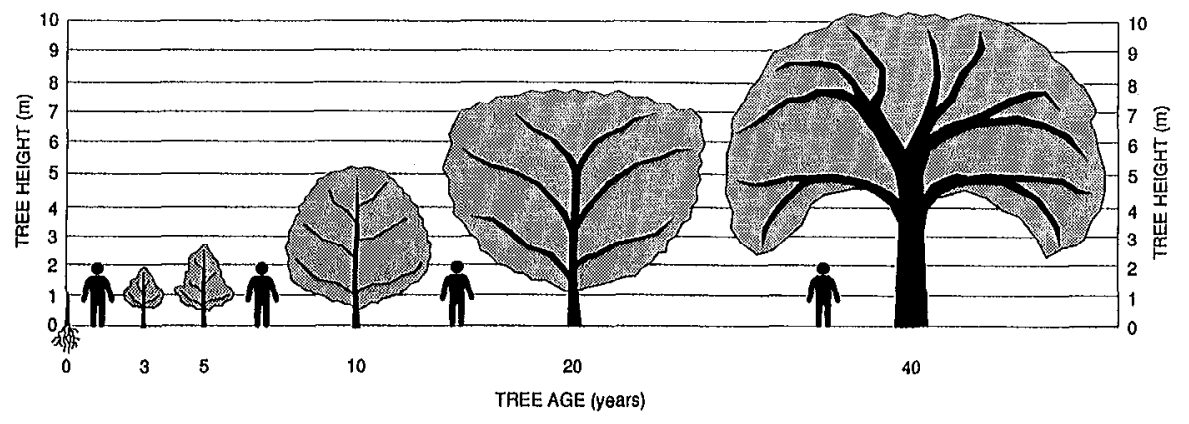

Fig. 1. Lifetime canopy developmental pattern for a standard-sized apple tree.

and small hedgerow trees was similar, but the cross-section of small trees allowed for better light illumination of the interior portions of the canopy (Verheij and Verwer, 1973). Heinicke (1964) also found that as tree size decreased, the heavily shaded area within the tree decreased. Per tree leaf area decreased with smaller tree size but per hectare leaf area increased. Dwarf trees with some overlap of canopies had one-third more leaf area per hectare that received $>30 \%$ of full sun than did standard trees. This indicates a distinct advantage in photosynthetic potential for smaller trees. Forshey and McKee (1970) reported that a large and small tree had the same total dry matter accumulation per unit of occupied land, despite the lower leaf area index (LAI) on the smaller tree. The small tree had a more efficient leaf surface and produced $80 \%$ more fruit per unit of occupied land than the big tree. Cain (1970) showed a negative linear relationship between production per unit of tree area and the size of the tree. The relationship showed a decrease of $0.6 \mathrm{~kg} \cdot \mathrm{m}^{-2}$ for each meter increase in tree spread. The decreased efficiency of large trees is likely the result of greater internal shading.

\section{The central leader tree}

The benefits of smaller trees led to the development of the "Central Leader" (C.L.) tree form by Heinicke (1975) and McKenzie (1972). This tree training system has been widely adopted in North America, New Zealand, Australia, and South Africa. The system has a pyramid-shaped tree with tiers of branches spaced along the trunk. The widest part of the tree is at the bottom tier. Years of experience have led growers to increase the distance between the bottom and second tier to a minimum of $1 \mathrm{~m}$ and to leave gaps in the canopy to increase the light penetration to the bottom tier. Barritt et al. (1991) have reported on the seasonal change in interior canopy light climate of 'Delicious' central leader trees. Their data show a rapid decline in light exposure to $<20 \%$ full sun by early June for the interior parts of the canopy. The rapid seasonal decline in light exposure of the interior of central leader trees has led to summer pruning to improve fruit color with most of the cultivars grown in the eastern United States.

Recently we characterized the light climate in mature central leader 'Empire'/M.7 and mini-central leader Empire/M.9/MM.111 trees (Interstems) four times during the growing season to examine the effect of tree size and summer pruning on light exposure in the

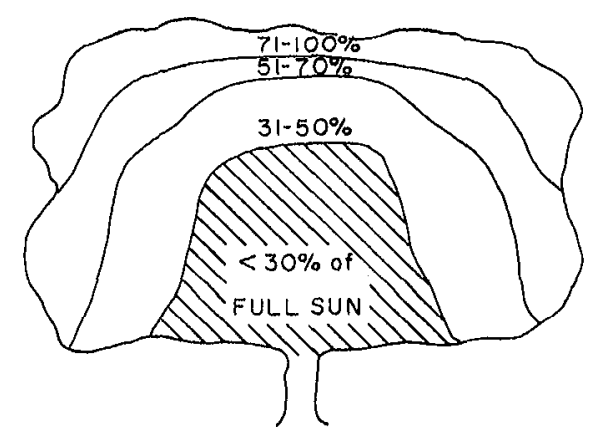

Fig. 2. Light distribution in a large round-crowned 'Delicious' apple tree (from Mooney, 1968). lower part of the canopy. The trees were well-trained central leaders with three tiers of permanent branches for the M.7 trees and two tiers of permanent branches for the Interstem trees. There was $1 \mathrm{~m}$ between each tier. At each date, the canopy light profile was measured by fisheye photography using north-south and east-west transects. The light data were used to categorize the canopy profile into three light zones: 1) well-exposed zone with light levels $>50 \%$ of full sun; 2) marginally exposed zone with light levels between $30 \%$ and $50 \%$ of full sun; and 3 ) a poorly exposed zone with light levels $<30 \%$ of full sun. At 14 days after full bloom (DAFB) most of the lower interior portion of the M.7 tree canopy already had poor light exposure ( $<30 \%$ full sun), while only a very small portion of the Interstem tree canopy was poorly illuminated (Figs. 3 and 4). In the M.7 trees, a significant portion was marginally exposed as well. At 44 DAFB, the area of poorly illuminated and marginally exposed canopy areas had increased in both tree types but a higher proportion of the interstem canopy was well exposed. At 74 DAFB, the relative areas of poorly and marginally illuminated areas were smaller in the interstem tree than in the M.7 trees; however, both tree types had large areas of poorly illuminated canopy areas. At 100 DAFB, the trees were summer pruned by removing upright shoots in the first and second tiers. Summer pruning improved light distribution in the middle section of the canopy for both tree types. The area of poorly exposed canopy in the interstem tree was reduced to a small area near the trunk on the bottom tier of branches. With the larger M.7 trees, the area of low light level was larger and the area of marginally exposed canopy was not reduced as much by summer pruning. We observed that there was very little fruit in the lower interior part of the M.7 trees while the interstem trees had fruit in all parts of the canopy. Although summer pruning improved the light distribution of the M.7 canopy, it may have been too late in the season to have much of an effect on fruit bud differentiation. Lakso et al. (1989b) have shown that many of the detrimental effects of canopy shade on fruit development can be attributed to early season light exposure. The improved light distribution of the interstem trees results from the smaller height and depth of the canopy and the greater relative distance of the $1 \mathrm{~m}$ distance between scaffold branches in the interstem canopy than in the bigger M.7 trees.

\section{The palmette leader tree}

In many cases as central leader trees age, the upper limbs outgrow the bottom of the tree, resulting in excessive shade in the bottom of the trees. There is a strong tendency for the upper scaffold limbs to grow more vigorously than the lower limbs due to better exposure. The shading that develops reduces flowering and fruiting in the center of the tree. Lakso et al. (1989a) described a modification of the central leader tree form named the palmette leader (PL) designed to improve the light distribution of the tree canopy. This tree form is developed by removing upper east- and west-growing branches, thus creating large gaps in the canopy on the east and west sides of the tree. This change results in a flat north-south oriented palmette top. The lower tier of limbs is left intact. The primary advantage of the PL form is that the large gaps in the upper east and west sides of the tree guarantee good light exposure to all parts of the tree (Fig. 5). A more subtle benefit is that good light penetration into the tree center is maintained throughout the season. 


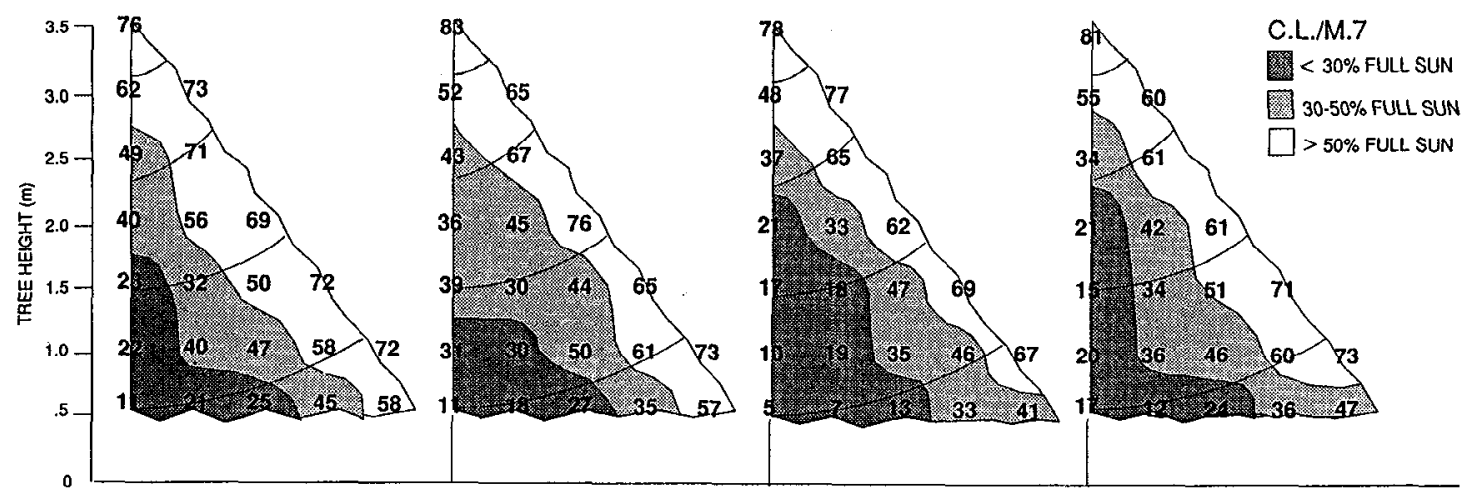

Fig. 3. Canopy light distribution pattern at four times during the growing season for H-year-old 'Empire'/M.7 apple trees trained as central leaders. Values are percent full sun as determined by fisheye photography, $n=3$.

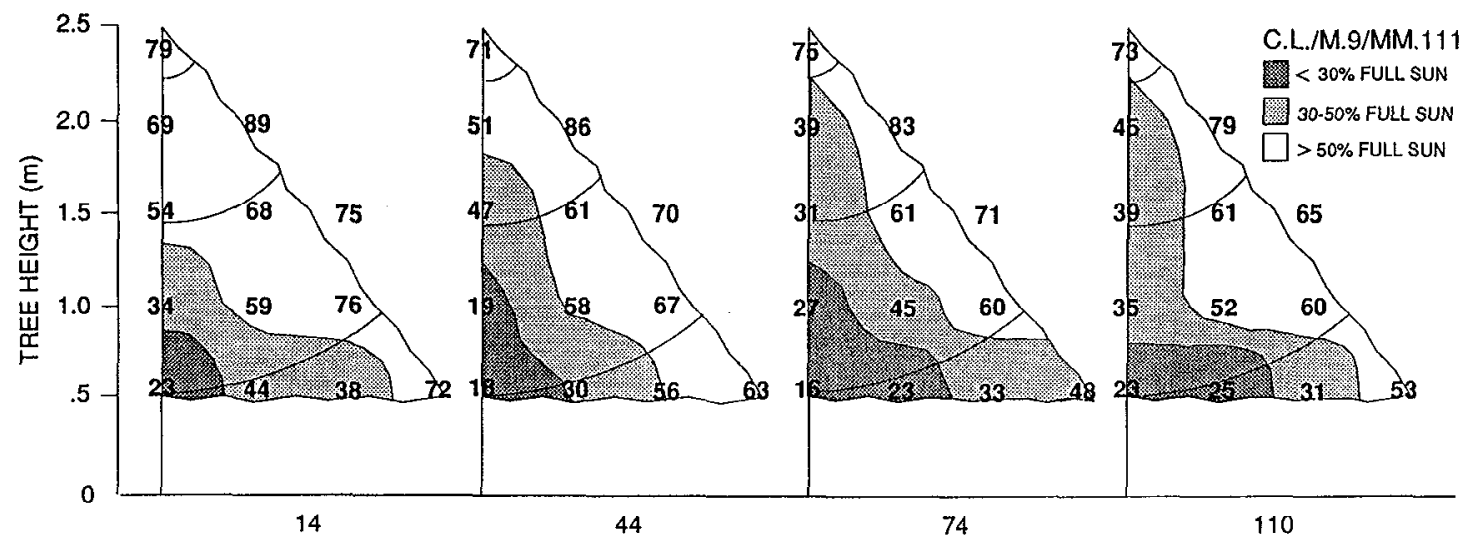

Fig. 4. Canopy light distribution pattern at four times during the growing season for 11-year-old 'Empire'/M.9/M.111 (Interstem) trees trained as mini-central leaders. Values are percent full sun as determined by fisheye photography, $\mathrm{n}=3$.

This is particularly important since many of the processes critical to fruit production, such as flower bud development and fruit cell division occur in the first 3 to 6 weeks after full bloom (Westwood, 1978).

A useful feature of the narrow north-south palmette top is that it improves the exposure of the north side of the tree. Because of this, the advantages of north-south oriented canopies can be obtained in east-west oriented rows. In an east-west planted row, the leader of the PL trees may still be oriented north-south (i.e., perpendicular to the row direction). This creates a gap between trees in the row for light penetration to the lower limbs of the canopy (Fig. 6)

This tree form is most useful as a conversion form when semidwarf to semi-vigorous central leader trees are 7 to 15 years old. At this age, upper tier limbs are still small and the conversion can be accomplished by removing two to three upper tier east- or westgrowing limbs each year for 3 years. This can result in little or no depression of tree yields. As trees age, large limbs must be removed to make the conversion to a PL and care should be taken to make the conversion slowly, over several years, so that excessive vigor and a reduction in yield are not induced.

Pruning of this tree form is simple compared with the central leader tree, since light does not have to filter through layers of canopy. Pruning consists of keeping a narrow palmette top in the north-south direction, thinning out excess limbs in the top, and removing upright growth from the bottom whorl of scaffolds. Maintenance of the basic geometric form is easy to teach to pruners since a high level of skill is not required.

\section{The slender spindle tree}

The slender spindle tree is a narrow, fully dwarf tree developed to allow planting of very high tree densities in either single, double, triple, or multiple-row beds to improve the early yields of apple orchards (Wertheim, 1968). It is designed for greater biological and management efficiency by allowing all management to be done from the ground. The width of the canopy is $\leq 2 \mathrm{~m}$, which should ensure that most of the canopy is well exposed. However, in this case, the branches may be close together with only small gaps in the canopy, resulting in a high density of foliage in the tree. With moderate to vigorous growth, these gaps can be closed very quickly in the season, thus leading to poor fruit color and quality if the trees are not summer pruned (Corelli and Sansavini, 1989). Sansavini et al. (1981) found under vigorous growth conditions that light levels in the lower part of the canopy of a bed system were lower than in a medium density palmette hedgerow.

In our study described above, slender spindle trees of 'Empire'/ M.9 had very good light exposure in most of the canopy at 14 DAFB (Fig. 7). All parts of the canopy had $>30 \%$ full sun and only a small portion in the bottom was $<50 \%$ full sun. However, by 44 DAFB, light exposure levels in all but the top of the tree had dropped considerably, indicating that the gaps between limbs had been closed. By 74 DAFB, there was a large, poorly illuminated area of the canopy. Summer pruning markedly reduced the poorly illuminated area of the canopy, but the marginally illuminated area remained much the same and only the top of the tree was well exposed. With summer pruning, only upright shoots were removed, 
PALMETTE LEADER TREE

East-West Transect

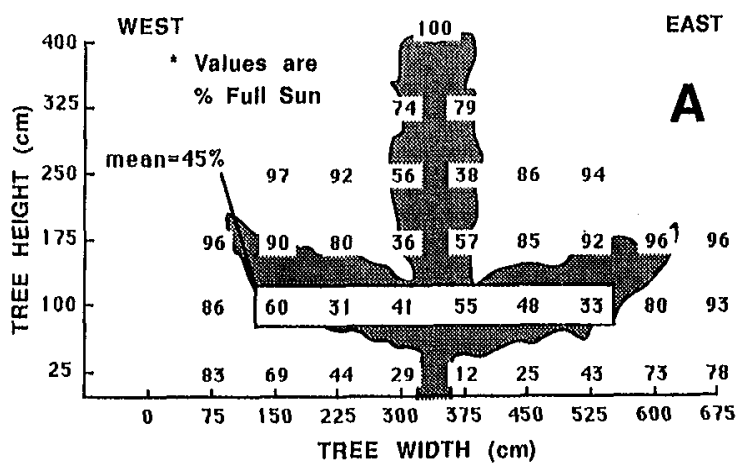

CENTRAL LEADER TREE

East-West Transect

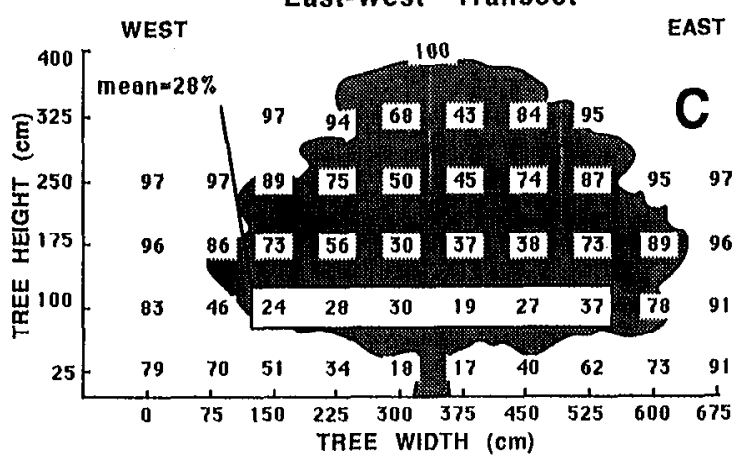

PALMETTE LEADER TREE

North-South Transect

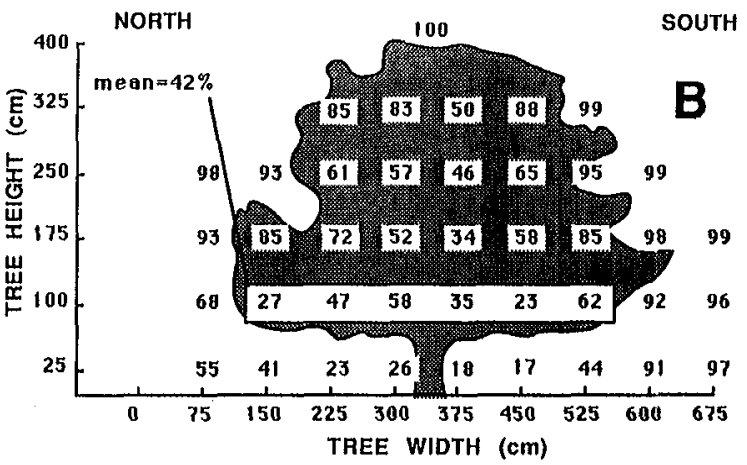

CENTRAL LEADER TAEE

North-South Transect

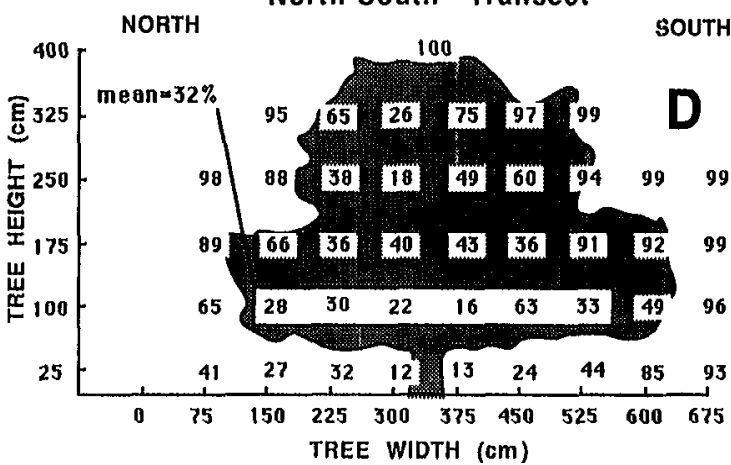

Fig. 5. Transects of light availability in a palmette leader (A and B) and a central leader (C and D) tree. Values are percent full sun as determined by fisheye photography (from Lakso et al., 1989a).
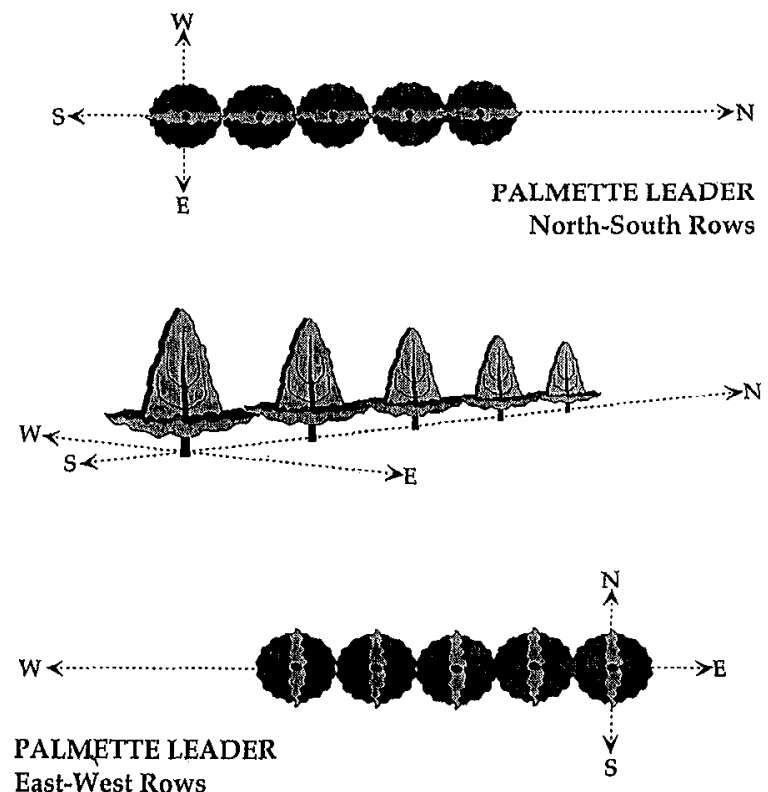

East-West Rows

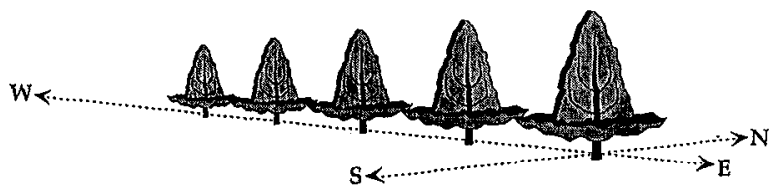

Fig. 6. Schematic of palmette leader tree form in north-south and eastwest oriented rows.

but in the compact tree of the slender spindle, the spur and bourse shoot leaves also account for much of the shading. Our experience with cultivars like 'Empire' indicates that summer pruning of slen- der spindle trees is essential for good fruit color. The challenge with slender spindle trees is to combine the correct vigor control techniques and pruning with spacing. Incorrect choice of tree spacing or excessive vigor can result in excessive shade due to the limited area allotted to each tree.

\section{Thin restricted plane canopy trees}

Planar canopies have been developed to overcome the problems of light penetration into thick canopies. Examples are thin narrow hedgerows, tree walls, vertical low and high trellis, Ebro trellis, and $\mathrm{A}, \mathrm{V}$, and $\mathrm{T}$ trellises. Since the foliage and limbs are restricted to a single plane, these tree forms usually have a dense canopy that is essentially nontransmitting. The rule of thumb of $1 \mathrm{~m}$ of light penetration into canopies does not hold in this case. With the horizontal planar canopies, such as the $\mathrm{T}$ or Ebro trellis, there is a drastic reduction in light levels from the top to the bottom of the canopy. Ferree et al. (1989) reported that the Lincoln canopy (Ttrellis) had a high transmission of light through the canopy following severe dormant pruning, but, with moderate pruning, the canopy had very low transmission values. In the Ebro trellis, which is a four-tier horizontal canopy system, Tustin et al. (1989) found low light transmission through the top layer of the trellis resulting in excessive shade to the lower layers. These horizontal canopy systems were developed for mechanization of harvest but they suffer from the horticultural problems of excessive upright shoot growth from the top side of the trellis. This increases the amount of shading and, in the case of the Ebro trellis, can result in complete closure of the space between tiers. Our experience in New York with red cultivars like 'Empire' shows that fruit color with horizontal trellises is poor and canopy development has been slow due to the flat limb orientation.

Inclined V- or A-shaped canopies were also developed for mechanical harvest, but they overcome many of the horticultural problems of the horizontal canopies. Very high yields have been reported with these systems (Hutton et al., 1987; Robinson and Lakso, 1989; van den Ende et al., 1987). Light distribution in these systems depends on light transmission through the canopy and direct light 


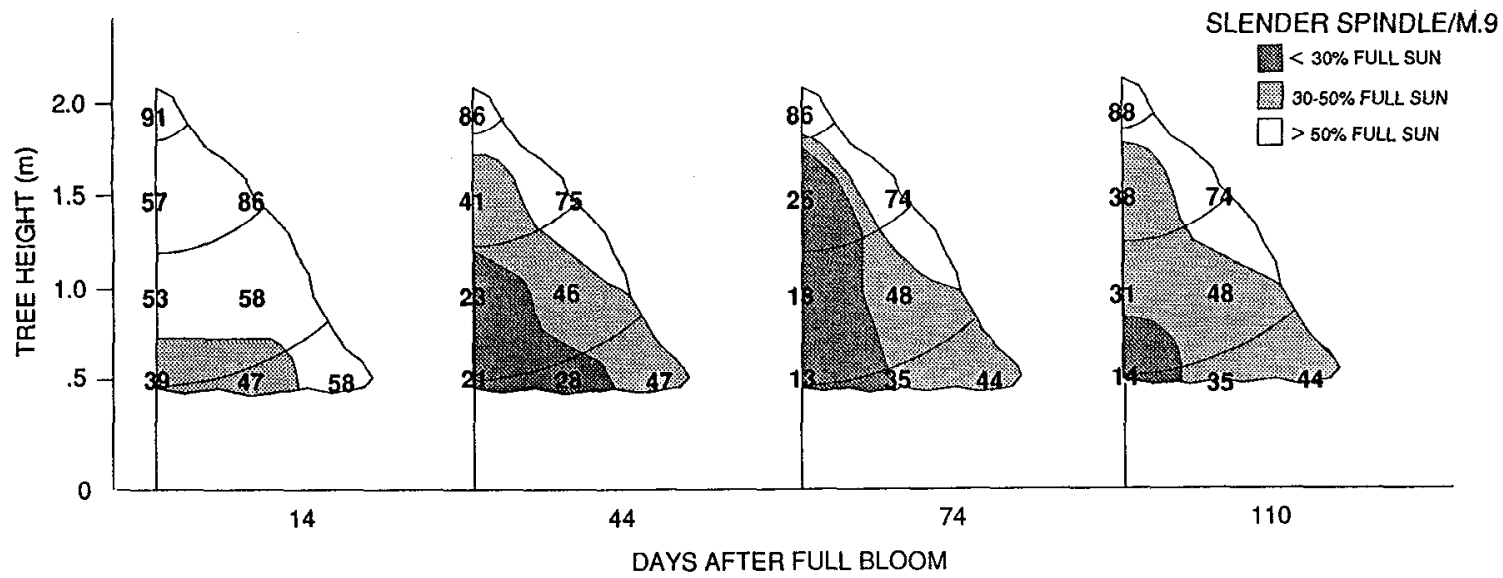

Fig. 7. Canopy light distribution pattern at four times during the growing season for 11-year-old 'Empire'/M.9 trees trained as slender spindles. Values are percent full sun as determined by fisheye photography, $\mathrm{n}=3$.

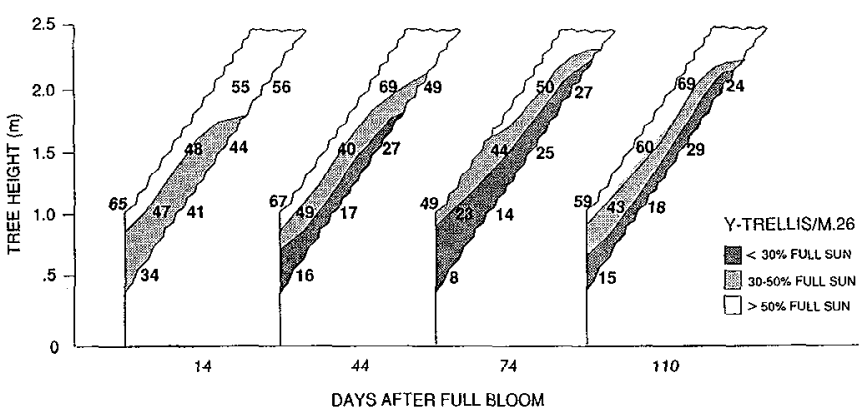

Fig. 8. Canopy light distribution pattern at four times during the growing season for 11-year-old 'Empire'/M.26 trees trained as a Y-shaped hedgerow. Values are percent full sun as determined by fisheye photography, $\mathrm{n}=3$.

exposure of the underside of the trellis through the open gap at the top of the canopy arms. In our study described above, a dwarf version of a Y-shaped hedgerow had very good light exposure at 14 DAFB, with no part of the canopy receiving $<30 \%$ of full sunlight (Fig. 8). By 44 DAFB, there was a strong gradient of light through the canopy with the interior of the $\mathrm{Y}$ receiving $>50 \%$ full sun while the underside of the Y received $<30 \%$. By 74 DAFB, only the top interior portion of the $\mathrm{Y}$ was well illuminated. Summer pruning, which consisted of removal of unwanted watersprouts in the interior of the $\mathrm{Y}$, increased the exposure at the center of the $\mathrm{Y}$. However, the underside of the trellis remained below $30 \%$ full sun. In this study the canopies of adjacent rows had closed, which allowed little light to the underside of the Y. Our experience with this system indicates that when the canopies of adjacent rows touch, fruit color and quality on the underside of the trellis decline. If a minimum of $1.5 \mathrm{~m}$ of open space is maintained between the $\mathrm{Y}$ arms, fruit color is good.

Thin vertical canopies receive light exposure from both sides of the canopy and so should have good light distribution within the canopy. Ferree (1980) reported that a palmette hedgerow had better light penetration into the canopy than did slender spindle, interstem, or pyramid hedgerow trees. The trellis also had greater crop density and greater efficiency than the other systems. Experience in New York suggests that, if the trellis canopies are kept thin, they produce excellent fruit quality. However, as the width of these canopies increases, the center of the canopy produces poor quality fruit. With wide palmette trellis hedgerows. Ferree et al. (1989) found light transmission to be similar to the slender spindle. The vertical stacking of fruiting branches with palmette trellis hedgerows leads to more growth on the top branches than on the bottom branches due to better light exposure. If not carefully managed, the top branches shade the lower ones, resulting in loss of vigor and fruit quality in the bottom of the tree.

\section{LIGHT INTERCEPTION BY ORCHARD CANOPIES}

The theory of light interception has been reviewed several times (Cain, 1972; Jackson, 1980,1985; Jackson and Palmer, 1972; Sansavini, 1982). Mathematical models of light interception have also been constructed (Jackson, 1981; Palmer, 1981). From this body of work a few main points are important for this discussion. Orchard canopies, unlike those of other crops, are of necessity discontinuous due to the alleyways maintained between rows for orchard machinery, which results in a large proportion of the land area not covered by trees (Jackson, 1980). This distribution results in low values for LAI and total light interception for orchard canopies compared with other crops. In addition, leaf area is not randomly distributed over the land area as in annual crops but is clumped in trees,, branches, and spurs. Light interception is low when the orchard is planted and increases as the orchard develops in relation to total LAI. Light interception in orchards can be raised by: 1) increasing the density of foliage in the canopy, 2) increasing the height of the trees relative to the clear alley width, or 3) increasing the number of trees per hectare (Corelli and Sansavini, 1989). Because of the tractor alleys used for orchard management, light interception is more strongly influenced by tree numbers per hectare and tree height : clear alley ratios than by canopy density.

Cain (1970) introduced the idea that orchard density should be considered over the lifetime of the orchard. He found that the mean lifetime fraction of land covered by tree canopy increased as tree size decreased. Light interception could also be considered over the lifetime of the orchard with a mean lifetime fraction of light intercepted. Several studies have examined light interception in mature and young orchards.

Jackson (1970) has shown that widely spaced bush trees, common in many older orchards and large at maturity, intercept very little light when they are young, yet when full-sized they have excessive within-tree shading and relatively low LAIs. The realization that significant land and light resources are wasted in the early life of an orchard has encouraged the planting of higher and higher tree densities. This practice has resulted in greater early yield and greater lifetime light interception. Verheij and Verwer (1973) examined light interception in low- and high-density hedgerows of 'Golden Delicious'. The low-density plots (1100 trees/ha on M.9 and 660 trees/ha on M.2) intercepted roughly half of the incident light at maturity and yields peaked at $40 \mathrm{t} \cdot \mathrm{ha}^{-1}$. The high-density plots (3300 trees/ha on M.9 and 2260 trees/ha on M.2 intercepted twothirds and three-quarters of available light, respectively. Yields were $>70 \mathrm{t} \cdot \mathrm{ha}^{-1}$ in their 6 th and 7 th years, but thereafter yields declined due to inter-tree competition.

In a spacing trial, Palmer and Jackson (1974) have reported that with densities ranging from 853 to 3746 trees/ha, yield and light interception were approximately linearly related. Light interception was closely related to LAI, not just trees per hectare. Wertheim et al. (1986) examined light interception of high-density single rows, 
three- and six-row bed and full-field systems. They found that light interception was positively related to tree density and yield. The effect of the tree arrangement was less important than number of trees/ha for increasing total light interception and yield. The results of tree arrangement showed that single-row or full-field arrangements of trees gave better yields than the three-row system at equivalent tree densities. Increasing tree planting density has been the most important means of increasing the early yield and early light interception of young orchards. Barritt (1989) found that tree density was more important than training system or rootstock for improving light interception and yield of 'Granny Smith' in the 3rd year.

To achieve high light interception with even light distribution, Palmer and Jackson (1977) developed a bed system with a more even distribution of foliage over the orchard floor. The bed system had trees spaced $1.5 \times 0.5 \mathrm{~m}$ in a 14-row bed separated by tractor alleyways. It achieved ceiling levels of LAI and light interception 2 years after planting. Interception was comparable to a closely planted hedgerow system $(2.9 \times 0.9 \mathrm{~m})$; yet the bed system had a much lower LAI due to a more even distribution of foliage over the orchard floor. They concluded that LAI was the largest single factor influencing light interception in discontinuous orchard canopies; however, the LAI/light interception relationship could be modified to some extent by leaf distribution pattern over the ground area. More recently, Palmer (1988) has shown that bed systems can intercept up to $80 \%$ of PAR from the end of June until October and yield $78 \mathrm{t}^{\mathrm{t}} \mathrm{ha}^{-1}$ in the $3 \mathrm{rd}$ year.

Intensive bed systems (Palmer and Jackson, 1977) or multirow systems (Wertheim et al., 1986) are not compatible with conventional orchard machinery and have not yet been adopted in the United States. However, there has been a strong move to smaller trees to allow all orchard management operations to be done from the ground. In many cases, the decrease in tree size has not been accompanied by a reduction in tractor alley width. This discrepancy has resulted in height : alley width ratios of $\leq 1$. Cain (1972) indicated that for optimum light interception the ratio should be 2 . Consequently, many dwarf orchards in New York have relatively low yields, presumably due to low light interception. However,

Table 1. Light interception in September by four orchard systems of 'Empire' and 'Delicious' apple trees (from Robinson and Lakso, 1989). ${ }^{2}$

\begin{tabular}{llccccc}
\hline & & \multicolumn{5}{c}{ PAR intercepted (\%) } \\
\cline { 3 - 7 } Cultivar & \multicolumn{1}{c}{ System } & 1984 & 1985 & 1986 & 1987 & Average \\
\hline \multirow{2}{*}{ Empire } & Slender Spindle/M.9 & $53 \mathrm{~b}$ & $45 \mathrm{~b}$ & $54 \mathrm{~b}$ & $51 \mathrm{~b}$ & $51 \mathrm{~b}$ \\
& Y-trellis/M.26 & $67 \mathrm{a}$ & $65 \mathrm{a}$ & $73 \mathrm{a}$ & $70 \mathrm{a}$ & $69 \mathrm{a}$ \\
& C.L./M.9/MM.111 & $45 \mathrm{c}$ & $40 \mathrm{c}$ & $43 \mathrm{c}$ & $45 \mathrm{~b}$ & $43 \mathrm{c}$ \\
& C.L./M.7 & $35 \mathrm{~d}$ & $37 \mathrm{c}$ & $47 \mathrm{bc}$ & $48 \mathrm{~b}$ & $42 \mathrm{c}$ \\
Delicious & Slender Spindle/M.9 & $29 \mathrm{~b}$ & $33 \mathrm{a}$ & $41 \mathrm{a}$ & $38 \mathrm{~b}$ & $35 \mathrm{~b}$ \\
& Y-trellis/M.26 & $41 \mathrm{a}$ & $38 \mathrm{a}$ & $48 \mathrm{a}$ & $46 \mathrm{a}$ & $43 \mathrm{a}$ \\
& C.L./M.9/MM.111 & $18 \mathrm{c}$ & $21 \mathrm{~b}$ & $25 \mathrm{~b}$ & $31 \mathrm{bc}$ & $23 \mathrm{c}$ \\
& C.L./M.7 & $17 \mathrm{c}$ & $19 \mathrm{~b}$ & $26 \mathrm{~b}$ & $29 \mathrm{c}$ & $22 \mathrm{c}$ \\
\hline
\end{tabular}

${ }^{2}$ Mean separation within columns and within each cultivar by Duncan's multiple range test, $P=0.05, \mathrm{n}=4$.

Table 2. Cropping efficiency based on light energy intercepted for 'Empire' and 'Redchief Delicious' apple trees under four management systems (from Robinson and Lakso, 1989).

\begin{tabular}{lllllll}
\hline \hline & & \multicolumn{5}{c}{ Cropping efficiency (g fruit/MJ PAR) } \\
\cline { 3 - 7 } Cultivar & \multicolumn{1}{c}{ System } & 1984 & 1985 & 1986 & 1987 & Cum. \\
\hline Empire & Slender Spindle/M.9 & $4.3 \mathrm{a}$ & $7.9 \mathrm{a}$ & $4.0 \mathrm{~b}$ & $4.0 \mathrm{~b}$ & $5.0 \mathrm{~b}$ \\
& Y-trellis/M.26 & $4.5 \mathrm{a}$ & $7.1 \mathrm{a}$ & $5.5 \mathrm{a}$ & $7.0 \mathrm{a}$ & $6.0 \mathrm{a}$ \\
& C.L./M.9/MM.111 & $3.4 \mathrm{~b}$ & $7.1 \mathrm{a}$ & $4.0 \mathrm{~b}$ & $3.6 \mathrm{~b}$ & $4.5 \mathrm{~b}$ \\
& C.L./M.7 & $1.1 \mathrm{c}$ & $5.3 \mathrm{~b}$ & $2.3 \mathrm{c}$ & $2.7 \mathrm{c}$ & $2.9 \mathrm{c}$ \\
Delicious & Slender Spindle/M.9 & $3.8 \mathrm{a}$ & $6.9 \mathrm{a}$ & $3.5 \mathrm{ab}$ & $2.5 \mathrm{~b}$ & $4.1 \mathrm{a}$ \\
& Y-trellis/M.26 & $2.3 \mathrm{~b}$ & $7.0 \mathrm{a}$ & $4.7 \mathrm{a}$ & $3.7 \mathrm{a}$ & $4.4 \mathrm{a}$ \\
& C.L./M.9/MM.111 & $2.5 \mathrm{~b}$ & $6.2 \mathrm{a}$ & $3.1 \mathrm{bc}$ & $2.5 \mathrm{~b}$ & $3.5 \mathrm{a}$ \\
& C.L./M.7 & $1.1 \mathrm{c}$ & $4.9 \mathrm{a}$ & $1.9 \mathrm{c}$ & $0.8 \mathrm{c}$ & $2.0 \mathrm{~b}$ \\
\hline
\end{tabular}

${ }^{2}$ Mean separation within columns and within each cultivar by Duncan's multiple range test, $P=0.05, \mathrm{n}=4$.

Cumulative cropping efficiency calculated using 4-year cumulative yield and intercepted PAR (1984-1987) these orchards do have better fruit quality than larger trees due to improved light distribution. Growers who desire a 2.5-m-tall tree should expect to reduce tractor alleys to $\leq 1.5 \mathrm{~m}$.

Few studies of light interception have been done with planar canopies. Palmer and Jackson (1977) reported that trees on semidwarfing rootstocks trained to tall narrow hedgerows separated by wide alleys achieved high light interception at maturity, but the between-row shading resulted in poor illumination of the lower portion of the hedgerow, which became unproductive. Shorter hedges on more dwarfing stocks inevitably have lower light interception if the alley width is maintained the same. Such short vertical trellised hedgerows are common in New York. But in many cases, tractor alley widths have remained too wide for optimum light interception and yields have been lower than expected. The recent introduction of narrow orchard tractors to the United States should help reduce tractor alleys.

Robinson and Lakso (1989) compared the relationship of tree density, light interception, and yield among four orchard systems. They found a linear relationship between yield and tree density over the first 10 years of the orchard life for three pyramid-shaped systems. The fourth system, a Y-trellised hedgerow, had greater yield than was predicted for its tree density. Light interception was highest with the Y-trellis and this accounted for a large portion of the increased yield (Table 1). The increased light interception was the result of a canopy architecture that allowed the tree canopy to grow over the tractor alleys. In this study, the Y-trellis intercepted $\approx 70 \%$ of available PAR at maturity while the slender spindle system intercepted only $55 \%$ of PAR in spite of $30 \%$ greater tree density. This difference illustrates the problem of short stature trees planted in single rows where mature light interception is relatively low due to a low tree height : clear alley ratio. The Y-trellis, because of its unique geometric shape, had interception levels similar to the bed systems of Palmer (1988) or the multiple rows of Wertheim et al. (1986) yet could be maintained with conventional equipment. We found no studies on the light interception properties of other planar canopy tree forms.

\section{EFFICIENCY COMPARISONS}

Long-term comparisons of efficiency between tree forms or orchard systems have been few. Ferree (1980) compared slender spindle (2151 trees/ha), palmette trellis (1121 trees/ha), interstem hedgerow (795 trees/ha) and pyramid hedgerow (425 trees/ha). The pyramid hedgerow had the greatest LAI but poor illumination within the canopy. Yields per hectare were related to tree density, but the trellis had significantly greater production efficiency (kilograms of fruit produced per unit of TCA). The lower efficiency of the highdensity slender spindle was attributed to excessive vigor that required more pruning to contain the trees to their allotted space. The interstem system was intermediate in efficiency but had the most open canopy and the best light penetration of the four systems. The least efficient system was the pyramid hedgerow.

There have been two reports comparing efficiency on the basis of light-energy intercepted. Palmer (1988) compared 'Crispin'/M.27 apple trees trained to a bed system at four spacings. He reported no clear effect of spacing on efficiency of conversion of PAR into fruit dry matter with an efficiency range of 1.04 to $1.24 \mathrm{~g}$ fruit dry weight/MJ PAR. His results suggest that differences in yield are due strictly to differences in light interception and not in efficiency of converting intercepted PAR into fruit.

Robinson and Lakso (1989) compared 'Empire' and 'Delicious' in four growing systems (Table 2). With 'Empire', the highest efficiency was with the Y-trellis/M.26 system (0.96 g fruit dry wt/ MJ PAR); followed in order by the slender spindle/M.9, interstem, and central leader/M.7 systems ( $0.46 \mathrm{~g}$ fruit dry wt/MJ PAR). The highest reported efficiency values in this study were lower than those reported by Palmer (1988). This difference likely was due to greater efficiency of the M.27 rootstock and the large-fruited triploid cultivar Crispin used in Palmer's study. The range of efficiencies reported in our study indicates that over large differences in tree size and form, there are differences in efficiency of converting intercepted PAR into fruit in addition to differences in light 
interception. These different efficiencies explain part of the differences in yield and could be due to light distribution patterns in the canopy as well as to differences in flower bud formation, fruit set, thinning, frost, etc.

\section{SUMMARY}

From the many studies of apple tree canopy modification the following conclusions can be made:

1) Light has a primary influence on fruit yield and fruit quality. The complexity of an orchard canopy results in leaves and fruit growing in a wide range of light intensities from full sunlight to a fraction of the total.

The rational management of apple canopies requires an understanding of light interception and distribution because canopies can be modified at will by pruning methods, tree training to control tree form, rootstock and scion cultivar selection to control tree size, and tree spacing to control orchard density.

3) Light distribution generally improves as tree size and canopy depth decrease. Efficiency of fruit management and biological efficiency are greater for small trees.

4) If the canopy has gaps that become filled with shoot growth soon after full bloom ( $<30$ DAFB), then summer pruning is essential to obtain good fruit color (i.e., the slender spindle tree). If the canopy has larger gaps that remain open for longer in the season, then the need for summer pruning is less (i.e., the palmette leader).

5) Planar canopies provide improved light exposure on the sides of the canopy. Horizontal canopies suffer from a shaded underside and excessive vegetative vigor. Vertical planar canopies have good light exposure on both sides of the canopy but have vertical stacking of fruiting branches leading to loss of vigor in the bottom of the tree. Inclined planar canopies (e.g., the Y-trellis) overcome the horticultural problems of the horizontal canopies and provide light exposure to both sides of the Y. In addition, they do not vertically stack the fruiting branches.

6) Early in the life of the orchard, light interception is a function of tree planting density. The best way to increase early yield is to increase planting density.

7) Light interception by a mature orchard is a function of the tree height : alley width ratio and the density of the canopy. If tree height is reduced without a compensatory reduction in tractor alley width, then light interception and yield will be low.

8) With fully dwarf, conic-shaped trees (2.2 m tall), high light interception $(70 \%$ to $80 \%)$ can only be obtained with multiple-row or full-field systems.

9) Vertical planar canopies must be tall or have narrow tractor alleys to optimize light interception.

10) The inclined planar canopy (Y-trellis) provides high light interception at moderate tree densities due to the geometric form of the canopy where Y arms grow up over the tractor alley,

11) High yield and high fruit quality come from combining good light distribution in the canopy and high light interception. High tree density combined with thin canopy depths (i.e., slender spindle or vertical trellis) provides high yields and high efficiency. The Ytrellis also combines high light interception and good light distribution resulting in high yields and high cropping efficiency.

\section{Literature Cited}

Barritt, B.H. 1989. Influence of orchard system on canopy development, light interception and production of third year 'Granny Smith' apple trees. Acta Hort. 243:121-130.

Barritt, B.H., C.R. Rom, B. Konishi, and M.A. Dilley. 1991. Light level influences spur quality and canopy development and light interception influence fruit production in apple. HortScience 26(8):993-999.

Cain, J.C. 1970. Optimum tree density for apple orchards. HortScience 5:232-234.

Cain, J.C. 1972. Hedgerow orchard design for most efficient interception of solar radiation. Effects of tree size, shape, spacing and row direction. N.Y. Agr. Expt. Sta. Search Agr. 2(7):1-14.

Chalmers, D.J. and B. van den Ende. 1975. The "Tatura Trellis": A new design for high yielding orchards. J. Agr. Victoria 73:473-476.

Corelli, L. and S. Sansavini. 1989. Light management and photosynthesis related to planting density and canopy management in apple. Acta Hort. 243:159-174.
Dunn, J. and M. Stolp. 1987. Apples on the Lincoln Canopy-mechanized management. HortScience 22:568-572.

Ferree, D.C. 1980. Canopy development and yield efficiency of 'Golden Delicious' apple trees in four orchard management systems. J. Amer. Soc. Hort. Sci. 105:376-380.

Ferree, D.C., J.R. Schupp, S.H. Blizzard, T.A. Baugher, and I.J. Warrington. 1989. Influence of five orchard management systems on canopy composition, light penetration and net photosynthesis of 'Golden Delicious' apple. Acta Hort. 243:131-140.

Forshey, C.G. and M.W. McKee. 1970. Production efficiency of a large and a small 'McIntosh' apple tree. HortScience 5:164-165.

Heinicke, D.R. 1963. The micro-climate of fruit trees. II. Foliage and light distribution patterns in apple trees. Proc. Amer. Soc. Hort. Sci. 83:111

Heinicke, D.R. 1964. The micro-climate of fruit trees. III. The effect of tree size on light penetration and leaf area in 'Red Delicious' apple trees. Proc. Amer. Soc. Hort. Sci. 85:33-41.

Heinicke, D.R. 1975. High density apple orchards-planning training and pruning. U.S. Dept. Agr. Hdbk. 458.

Hutton, R.J., L.M. McFadyen, and W.J. Lill. 1987. Relative productivity and yield efficiency of canning peach trees in three intensive growing systems. HortScience 22:552-560.

Jackson, J.E. 1970. Aspects of light climate within apple orchards, J. Applied Ecol. 7:207-216.

Jackson, J.E. 1980. Light interception and utilization by orchard systems. Hort. Rev. 2:208-267.

Jackson, J.E. 1981. Theory of light interception by orchards and a modeling approach to optimizing orchard design. Acta Hort. 114:69-79.

Jackson, J.E. 1985. Future fruit orchard design: Economics and biology, p. 441-459. In: M.G.R. Cannel1 and J.E. Jackson (eds.). Attributes of trees as crop plant. Inst. Terrest. Ecol., Abbots Ripton, Hunt, U.K.

Jackson, J.E. and J.W. Palmer. 1972. Interception of light by model hedgerow orchards in relation to latitude, time of the year and hedgerow configuration and orientation. J. Applied Ecol. 9:341-358.

Jackson, J.E., J.W. Palmer, M.A. Perring, and R.O. Sharples. 1977. Effects of shade on the growth and cropping of apple trees. III Effects on fruit growth, chemical composition and quality at harvest and after storage. J. Hort. Sci. 52:267-282.

Lakso, A.N., T.L. Robinson, and S.G. Carpenter. 1989a. The palmette leader: A tree design for improved light distribution. HortScience 24:271275.

Lakso, A.N., T.L. Robinson, and R.M. Pool. 1989b. Canopy microclimate effects on patterns of fruiting and fruit development in apples and grapes, p. 263-274. In: C.J. Wright (ed.). Manipulation of fruiting. Proc. 47th Nottingham Easter School, Butterworths, London.

Lespinasse, J.M. and J.F. Delort. 1986. Apple tree management in vertical axis: appraisal after ten years of experiments. Acta Hort. 160:139-155.

Looney, N.E. 1968. Light regimes within standard size apple trees as determined spectrophotometrically. Proc. Amer. Soc. Hort. Sci. 93:1-6.

Luckwill, L.C. 1978. Meadow orchards and fruit walls. Acta Hort. 65:237243.

McKenzie, D.W. 1972. Intensive orchards in New Zealand. The Orchardist of N.Z. 44:175-181.

McKenzie, D.W., J.S. Dunn, M. Stolp, and R.J. Hutton. 1978. Horizontal canopy orchards for mechanical harvesting. Acta Hort. 65:267-276.

Palmer; J.W. 1981. Computed effects of spacing on light interception and distribution within hedgerow trees in relation to productivity. Acta Hort. 114:80-88.

Palmer, J.W. 1988. Annual dry matter production and partitioning over the first 5 years of a bed system of Crispin/M.27 apple trees at four spacing. J. Applied Ecol. 25:569-578.

Palmer, J.W. and J.E. Jackson. 1974. Effects of tree population and variations in spacing within and between rows of Golden Delicious on M.9. Rpt. E. Malling Res. Sta. for 1973:66-68.

Palmer, J.W. and J.E. Jackson. 1977. Seasonal light interception and canopy development in hedgerow and bed system apple orchards. J. Applied Ecol. 14:539-549.

Robinson, T.L., E.J. Seeley, and B.H. Barritt. 1983. Effect of light environment and spur age on 'Delicious' apple fruit size and quality. J. Amer. Soc. Hort. Sci. 108:855-861.

Robinson, T.L. and A.N. Lakso. 1989. Light interception, yield and fruit quality of 'Empire' and 'Delicious' apple trees grown in four orchard systems. Acta Hort. 243:175-184.

Rosati, P. 1978. Tall hedgerow orchards. Acta Hort. 65:255-260.

Sansavini, S. 1982. High density orchards of various crops. Proc. XXIst Intl. Hort. Cong. 1:182-197.

Sansavini, S., D. Bassi, and L. Giunchi. 1981. Tree efficiency and fruit quality in high-density apple orchards. Acta Hort. 114:114-136. 
Tukey, L.D. 1978. The thin-wall trellis hedgerow system. Acta Hort. 65:261266.

Tustin, S., P. Hurst, I. Warrington, and J. Stanley. 1989. Light distribution and fruit quality through multi-layered trellis apple canopies. Acta Hort. 243:209-212.

van den Ende, B., D.J. Chalmers, and P.H. Jerie. 1987. Latest developments in training and management of fruit crops on tatura trellis. HortScience 22:561-568

Verheij, E.W.M. and F.L.J.A.W. Verwer. 1973. Light studies in a spacing trial with apple on a dwarfing and a semi-dwarfing rootstock. Scientia Hort. 1:25-42.

Wertheim, S.J. 1968. The training of the slender spindle. Pub. Proefstation Fruiteelt, Wilhelmindadorp, Netherlands no. 7.

Wertheim, S.J., A. de Jager, and M.J.J.P. Duyzen. 1986. Comparison of single-row and multi-row planting systems with apple, with regard to productivity, fruit size and colour, and light conditions. Acta Hort. 160:243258.

Westwood, M.N. 1978. Temperate-zone pomology. W.H. Freeman, San Francisco. 